\title{
Reed Benhamou, Charles-Joseph Natoire and the Académie de France in Rome. A re-evaluation
}

\section{Katalin Bartha-Kovacs}

\section{(2) OpenEdition}

1 Journals

\section{Édition électronique}

URL : http://journals.openedition.org/studifrancesi/4372

DOI : 10.4000/studifrancesi.4372

ISSN : 2421-5856

Éditeur

Rosenberg \& Sellier

\section{Édition imprimée}

Date de publication : 1 septembre 2016

Pagination : 330

ISSN : 0039-2944

\section{Référence électronique}

Katalin Bartha-Kovacs, « Reed Benhamou, Charles-Joseph Natoire and the Académie de France in Rome. A re-evaluation », Studi Francesi [En ligne], 179 (LX | II) | 2016, mis en ligne le 01 septembre 2016, consulté le 18 septembre 2020. URL : http://journals.openedition.org/studifrancesi/4372 ; DOI : https://doi.org/10.4000/studifrancesi.4372

Ce document a été généré automatiquement le 18 septembre 2020.

\section{(c)}

Studi Francesi è distribuita con Licenza Creative Commons Attribuzione - Non commerciale - Non opere derivate 4.0 Internazionale. 


\title{
Reed Benhamou, Charles-Joseph Natoire and the Académie de France in Rome. A re-evaluation
}

\author{
Katalin Bartha-Kovacs
}

\section{RÉFÉRENCE}

REED BENHAMOU, Charles-Joseph Natoire and the Académie de France in Rome. A re-evaluation, Oxford, Voltaire Foundation, 2015, 254 pp.

1 Reed Benhamou, professeur émérite à l'Université de l'Indiana, est spécialiste des programmes éducationnels des académies artistiques françaises au XVIII siècle. Son nouveau livre est consacré à la réévaluation de la figure du peintre Charles-Joseph Natoire, jugée de façon fort contradictoire par ses contemporains. En 1752, lorsqu'il devient le directeur de la prestigieuse Académie de France à Rome, Natoire est un peintre estimé, mais 23 ans plus tard - critiqué pour sa faiblesse, son incompétence, la qualité de son travail artistique et sa bigoterie religieuse-, il est démissionné de ce poste et vers la fin du siècle il est presque oublié. Afin d'examiner le bien-fondé de ces accusations et de dévoiler les causes du changement de jugement à l'égard de cet artiste, Reed Benhamou entreprend un important travail de documentation: à part les documents écrits par les contemporains de Natoire, elle considère également les expériences parallèles de ses prédécesseurs et successeurs à l'Académie.

2 Le livre, qui s'ouvre avec une introduction succincte - précédée de deux listes relatives à l'Académie de France à Rome et aux données biographiques du peintre -, se compose de deux parties. La première, plus courte, est essentiellement biographique: elle est consacrée aux origines de Natoire, à ses relations familiales, à sa formation et à ses premiers succès artistiques. La seconde partie, plus longue, examine la période romaine de Natoire et compare ses expériences à celles des autres directeurs de l'Académie de France: presque tous disposaient d'un budget insuffisant et devaient apprendre sur 
place les tâches administratives. Reed Benhamou souligne toutefois la particularité de la situation de Natoire: celui-ci travaillait à une époque où les pensionnaires de l'Académie n'appréciaient guère ses efforts. De plus, Rome étant une ville papale, Natoire tenait au strict protocole religieux que certains élèves ne respectaient pas et leur directeur devait alors faire face à des rébellions des pensionnaires. La conclusion dresse un bilan convaincant des résultats présentés dans le livre et avance l'hypothèse que la cause de l'oubli de Natoire serait due, en grande partie, à son séjour prolongé à Rome. Si le peintre était resté à Paris, il n'aurait probablement pas été accusé d'incompétence pédagogique et administrative, et il se peut qu'il aurait connu une gloire pareille à celle de François Boucher. L'étude est complétée par deux séries d'appendices, regroupant des documents concernant l'art et les comptabilités de Natoire, ainsi que d'une bibliographie et d'un index.

Dans ce livre richement annoté, Reed Benhamou offre une lecture empathique des sources, manuscrites et imprimées. C'est en se basant sur ces documents qu'elle prétend réhabiliter l'image de Natoire dont elle reproduit même les fautes d'orthographe commises dans sa correspondance. Si ce peintre, injustement oublié, commence à être redécouvert, c'est grâce aux travaux de Reed Benhamou. Son ouvrage est pourtant consacré aussi à l'Académie de France à Rome. Le livre, qui donne la traduction en anglais des citations françaises figurant dans le texte, est destiné à un public anglophone intéressé à l'histoire des académies artistiques françaises au siècle des Lumières. On peut seulement regretter les quelques références à Wikipedia dans un ouvrage de si haute qualité ainsi que l'absence des images, qui auraient aidé le lecteur à revivre encore plus fidèlement l'histoire de l'Académie de France à Rome sous la direction de Natoire. 